\title{
MEMORIA Y JUSTICIA TRANSICIONAL EN LOS ACUERDOS DE PAZ DE COLOMBIA*
}

\author{
Jordi Palou-Loverdos \\ Abogado y CONSUlTOR NACIONAL E INTERNACIONAL EN RESOLUCIÓN \\ PACÍFICA DE CONFLICTOS
}

\section{Resumen}

El proceso de paz en Colombia ha culminado con unos acuerdos complejos, cuyo máximo reto es su implementación práctica. Resulta relevante la utilización de mecanismos de justicia formal, pero también de diversos mecanismos de justicia transicional no jurisdiccionales, con el fin de enfrentar los abusos del pasado. Las iniciativas institucionales y de la sociedad civil orientadas al esclarecimiento de la verdad son determinantes para el reconocimiento y el empoderamiento de las personas y los colectivos, las víctimas y, en general, aquellos que han resultado directa o indirectamente afectados por la violencia en Colombia. La memoria sobre los hechos constituye uno de los pilares de la conciencia individual y colectiva y para la convivencia en las diferencias, para evitar repeticiones lesivas o violentas.

Palabras clave: proceso de paz, abusos del pasado, justicia transicional, esclarecimiento de la verdad, memoria histórica, convivencia.

El autor: abogado acreditado ante la Corte Penal Internacional, mediador nacional e internacional, consultor en resolución pacífica de conflictos, justicia transicional y memoria histórica. Profesor universitario visitante de Rutgers State University of New Jersey-Center for the Study of Genocide and Human Rights (Estados Unidos), miembro del Human Rights Institute del International Bar Association, miembro fundador y vocal de la Junta de la Comisión de Justicia Penal International del ICAB, miembro de la Junta directiva de Novact-Instituto Internacional para la no-violencia activa, miembro del Patronato de la Fundación Carta de la Paz dirigida a la ONU. Correo electrónico: palou-rognoni.advocats@icab.cat

Recibido: 24 de Agosto de 2017; evaluado: 25 de septiembre de 2017; aceptado: 3 de enero de 2018

Esta contribución se enmarca dentro del proyecto Las fronteras de la memoria. Los derechos humanos como marco delimitador de la construcción de la memoria en Colombia, financiado mediante una ayuda a la investigación del Institut Catalá Internacional per la Pau en el marco de su Plan plurianual (2015RICIP00007). 


\title{
MEMORY AND TRANSITIONAL JUSTICE IN THE PEACE AGREEMENTS OF COLOMBIA
}

\author{
Jordi Palou-Loverdos \\ LAWYER AND PEACEFUL CONFLICT RESOLUTION CONSULTANT
}

\begin{abstract}
The peace process in Colombia has culminated with complex agreements, and the greatest challenge remains its practical implementation. It is important to use not only formal justice mechanisms, but also diverse non-jurisdictional mechanisms of transitional justice, in order to face the abuses of the past. Institutional and civil society initiatives aimed at clarifying the truth are crucial for the recognition and empowerment of individuals and groups, victims and, in general, those who have been directly or indirectly affected by violence in Colombia. The memory of the facts constitutes one of the pillars of individual and collective conscience, for a coexistence in difference and to avoid harmful or violent repetitions.
\end{abstract}

Keywords: peace process, abuses of the past, transitional justice, clarification of the truth, historic memory, coexistence.

Author: Accredited attorney before the International Criminal Court, national and international mediator, consultant in peaceful resolution of conflicts, transitional justice, and historical memory. Visiting professor at the Rutgers State University of New Jersey-Center for the Study of Genocide and Human Rights (United States), member of the Human Rights Institute of the International Bar Association, founding member and chair of the Board of the International Criminal Justice Commission of the Barcelona Bar Association (ICAB), member of the Board of Directors at Novact-International Institute for Active Non-Violence, member of the Board of the Foundation Letter of Peace addressed to the UN. Email: palou-rognoni.advocats@icab.cat

Received: August 24, 2017; evaluated: September 25, 2017; accepted: January 3, 2018 


\section{Introducción}

Colombia se encuentra en un momento clave. Los retos del presente exigen enfrentar los abusos del pasado, de modo que permitan aproximarse a nuevos horizontes para encarar un futuro más equitativo para los ciudadanos, las comunidades, las organizaciones y el país. Nos hallaríamos aquí ante un modelo opuesto al español: en ese país, luego de una larga dictadura militar que tomó el poder tras su victoria en una cruenta guerra civil, la transición al nuevo sistema político se levantó sobre la base del olvido de los abusos del pasado y a partir de postulados reformistas (no de ruptura) que buscaban constituir una democracia con miras al futuro; en Colombia se han promovido iniciativas transicionales desde las instituciones públicas y la sociedad civil mientras el conflicto aún pervivía, aunque con diferentes formas e intensidad, desde hace décadas. Aun cuando la estructura institucional colombiana ha hecho avances impresionantes, hablar de "posconflicto" en Colombia podía resultar discutible, hasta que el Congreso colombiano ratificara los acuerdos de paz alcanzados entre el Gobierno y las FARC, como se explicará más adelante.

\section{Gestionar el pasado y el presente en Colombia}

La gestión de los abusos del pasado, el presente y, en especial, la implementación de los Acuerdos de paz del 24 de noviembre de 2016, ${ }^{1}$ con sus múltiples previsiones jurisdiccionales y no jurisdiccionales, medidas reparatorias, medidas de reconocimiento de las víctimas y medidas orientadas hacia la verdad y la memoria sobre los abusos del pasado, entre otras, constituyen enormes retos para el pueblo colombiano y para las iniciativas y políticas de cooperación internacional, tanto para la institucionalidad como para la sociedad civil. De forma complementaria, hay que tener en cuenta los escasos avances en las conversaciones entre el Gobierno colombiano y el Ejército de Liberación Nacional (ELN) desde sus inicios en febrero de 2017. De hecho, ese proceso ha quedado virtualmente suspendido ante la situación en la que algunos organismos y observadores nacionales e internacionales consideran que el ELN o algunos de sus miembros prosiguen con acciones violentas o armadas.

Existen grupos de delincuencia organizada y otros grupos que perpetran acciones violentas en Colombia, algunos en los territorios abandonados por las FARC como

\footnotetext{
Gobierno Nacional y Fuerzas Armadas Revolucionarias de Colombia-Ejército del Pueblo, "Acuerdo final para la terminación del conflicto y la construcción de una paz estable y duradera", http://www.altocomisionadoparalapaz.gov.co/procesos-y-conversaciones/Documentos\%20compartidos/24-11-2016NuevoAcuerdoFinal. pdf (acceso mayo 23, 2017).
} 
consecuencia de la firma del Acuerdo de paz. Hay denuncias de recientes crímenes continuados contra líderes sociales y se discute si se trata solo de una multiplicidad de actos o de una dinámica sistemática, incluso una vez firmados los acuerdos de paz en $2016 .^{2}$

En este marco, cabe recordar que Colombia ha sido capaz de proponer iniciativas significativas, no sin controversia interna, como la Ley de justicia y paz de 2005 y otras de memoria nacional, ${ }^{3}$ local y regional ${ }^{4}$ a partir de mandatos legales o impulsos concertados con las víctimas, sus familiares y la sociedad civil.

La Ley 975 de 2005, de justicia y paz, reinterpretada por la Sentencia C-5301 de 2006 del Tribunal Constitucional colombiano, señala:

La presente ley tiene por objeto facilitar los procesos de paz y la reincorporación individual o colectiva a la vida civil de miembros de grupos armados al margen de la ley, garantizando los derechos de las víctimas a la verdad, la justicia y la reparación [...] el conocimiento de la historia de las causas, desarrollos y consecuencias de la acción de los grupos armados al margen de la ley deberá ser mantenido mediante procedimientos adecuados, en cumplimiento del deber a la preservación de la memoria histórica que corresponde al Estado [... . ${ }^{5}$

2 Carolina Moreno, "Denuncian asesinato de 94 líderes sociales en 2016", http://www.centrodememoriahistorica.gov.co/noticias/noticias-cmh/van-94-los-lideres-sociales-asesinados-en-el-2016 (acceso mayo 23, 2017).

3 Ver al respecto la destacable iniciativa del Centro Nacional de la Memoria de Colombia. Es loable la pretensión de no querer establecer una memoria (en singular) o una memoria oficial del conflicto, sino más bien un equilibrio dinámico y complejo de memorias (en plural) legítimas y rigurosas que permitan una aproximación omnicomprensiva del conflicto, de sus causas y consecuencias y faciliten revelar verdades ocultas y ocultadas sobre ataques sistemáticos a los derechos humanos fundamentales de los ciudadanos y sus principales responsables, dignificar a las víctimas y los espacios donde pudieran hallarse restos humanos o vestigios del conflicto armado que conduzcan, en la medida de lo posible, a cerrar adecuadamente procesos de duelo individuales y colectivos, así como llevar a cabo iniciativas para elaborar el pasado sin olvidarlo y proyectarse armónicamente. Ello es relevante tanto para hipotéticas acciones de justicia que pudieran acordarse con el fin de conocer los hechos del pasado, su impacto en las personas, las comunidades y los derechos individuales y colectivos, sus demandas y necesidades de reparación material y simbólica y la implementación de las conversaciones de paz, en las que quizá emergerán conectores negativos y positivos entre los actores y los afectados por el conflicto violento.

4 Ver al respecto las relevantes iniciativas del Centro de memoria, paz y reconciliación de Bogotá o el Museo Casa de la Memoria de Medellín, entre otras.

5 Congreso de la República de Colombia, Ley 975 de 2005, "Por la cual se dictan disposiciones para la reincorporación de miembros de grupos armados organizados al margen de la ley, que contribuyan de manera efectiva a la consecución de la paz nacional y se dictan otras disposiciones para acuerdos humanitarios" (Bogotá: Diario Oficial No. 45.980, 25 de julio de 2005), art. 1. 
Esta Ley buscaba un equilibrio entre la aplicación de justicia en tribunales nacionales y determinadas medidas favorecedoras de procesos conducentes a la paz, incluidas las iniciativas de memoria, que son conceptuadas legalmente como "deber del Estado". ${ }^{6}$ Se trataba de iniciativas institucionales que ofrecían la aplicación de penas de cinco a ocho años por delitos graves bajo confesión de desmovilizados del conflicto armado o bajo prueba del Estado; se intentó priorizar el eje de verdad (conocimiento sobre los hechos del pasado por parte de la familia, de la sociedad y del Estado, combinado con el "deber de la preservación de la memoria histórica" del Estado colombiano) sobre el de justicia (principios de retribución, prevención general positiva y negativa). Se criticó la exigencia abstracta de confesión o versión libre de los hechos del pasado que, en última instancia, en muchos casos no sirvió para conocer con profundidad el alcance de los hechos y menos aún sirvió a las víctimas, que no percibieron esfuerzos auténticos de verdad, justicia y reparación por parte de los beneficiados por la Ley; por el contrario, en ocasiones sirvió para revictimizarlas, ante la ausencia de empatía o compasión con su realidad individual y colectiva y una cierta reivindicación de los hechos investigados por parte de los victimarios. ${ }^{8}$ Conviene tener muy presentes estos antecedentes cuando se estudia cómo implementar las medidas jurisdiccionales y no jurisdiccionales del Acuerdo de paz.

Hacíamos referencia también a la existencia del Centro Nacional de Memoria, que inició su labor en medio del conflicto. El Centro ha expuesto con detalle el desafío que suponía adelantar políticas públicas de memoria en un marco de mandato legal y en medio de la confrontación y destacó las dificultades para los representantes institucionales de reconocer la existencia y pervivencia de una lucha armada.

Es destacable la publicación del informe ¡Basta ya! de este organismo público, cuya rigurosa documentación de violaciones sistemáticas de derechos humanos ha abarcado la memoria y las demandas conexas documentadas a favor de la verdad, la justicia y la reparación en el seno de las conversaciones de paz a las que se hará referencia. Tuve ocasión de comprobar personalmente el enorme interés público suscitado por la presentación del informe en Bogotá. El documento resalta su reto y su aportación fundamental en medio del conflicto:

Congreso de la República de Colombia, Ley 975 de 2005, art. 1.

Congreso de la República de Colombia, Ley 975 de 2005, art. 2.

Felipe Gómez Isa, Paramilitary Demobilization in Colombia: Between Peace and Justice, documento de trabajo núm. 57, editado por Fride, http://www.fride.org/download/WP57_Colombia_Desmili_ENG_abr08.pdf (acceso mayo 23, 2017). 
Este informe no es una narrativa sobre un pasado remoto, sino sobre una realidad anclada en nuestro presente. Es un relato que se aparta explícitamente, por convicción y por mandato legal, de la idea de una memoria oficial del conflicto armado. Lejos de pretender erigirse en un corpus de verdades cerradas, quiere ser elemento de reflexión para un debate social y político abierto. El país está pendiente de construir una memoria legítima, que no consensuada, en la cual se incorporen explícitamente las diferencias, los contradictores, sus posturas y sus responsabilidades, y, además, se reconozca a las víctimas. ${ }^{9}$

Dicho esto, podemos aproximarnos a la última iniciativa para alcanzar una paz duradera en Colombia: después de conversaciones exploratorias entre el 23 y 26 de agosto de 2012 se acordó iniciar conversaciones estables orientadas a la paz, en lo que se ha conocido como "conversaciones de paz de La Habana". A tal efecto, el acuerdo inicial de los diálogos de paz pone de manifiesto que:

Atendiendo el clamor de la población por la paz, y reconociendo que:

La construcción de la paz es asunto de la sociedad en su conjunto que requiere de la participación de todos, sin distinción, incluidas otras organizaciones guerrilleras a las que invitamos a unirse a este propósito;

El respeto de los derechos humanos en todos los confines del territorio nacional, es un fin del Estado que debe promoverse;

El desarrollo económico con justicia social y en armonía con el medio ambiente, es garantía de paz y progreso;

El desarrollo social con equidad y bienestar, incluyendo las grandes mayorías, permite crecer como país;

Una Colombia en paz jugará un papel activo y soberano en la paz y el desarrollo regional y mundial;

Es importante ampliar la democracia como condición para lograr bases sólidas de la paz; [...]

Hemos acordado [...] iniciar conversaciones directas e ininterrumpidas sobre los puntos de la Agenda aquí establecida, con el fin de alcanzar un Acuerdo Final para la terminación del conflicto que contribuya a la construcción de la paz estable y duradera [....$^{10}$

9 Grupo de Memoria Histórica, ¡Basta ya! Colombia: memorias de guerra y dignidad (Bogotá: Centro Nacional de Memoria Histórica y Departamento para la prosperidad social, 2016), 16.

10 Gobierno Nacional y Fuerzas Armadas Revolucionarias de Colombia-Ejército del Pueblo, "Acuerdo general para la terminación del conflicto y la construcción de una paz estable y duradera", http://www. 
A diferencia de Ruanda o España, por poner dos ejemplos de países que han sufrido violencia sistemática y graves abusos en diferentes momentos históricos y continentes, las iniciativas de justicia transicional que impulsen países como Colombia o la República Democrática del Congo ${ }^{11}$ para superar las violencias deberán tener en cuenta los principios y las normas internacionales contenidas en el Estatuto de la Corte Penal Internacional (CPI) respecto a abusos y crímenes internacionales perpetrados con posterioridad a 1 de julio de $2002 \cdot{ }^{12}$ sin duda, en cualquier conversación, acuerdo de justicia transicional, acuerdo de paz o su implementación en estos países deben equilibrarse los ejes de justicia y paz (además de las medidas de reparación a las víctimas y las garantías de no repetición y reforma institucionales), pues según el derecho internacional y el Estatuto de la CPI las amnistías generales sobre crímenes internacionales no están permitidas para grupos militares, grupos paramilitares, ejércitos regulares ni para representantes gubernamentales o estatales, incluidos jefes de Gobierno o del Estado. Ello ha sido y es realidad en el proceso de Colombia. ${ }^{13}$

altocomisionadoparalapaz.gov.co/procesos-y-conversaciones/acuerdo-general/Documentos\%20compartidos/ Acuerdo_General_para_la_terminacion_del_conflicto.pdf (acceso mayo 23, 2017).

11 País vecino de Ruanda, que soporta presencia militar directa o mediante grupos armados satélites de este último, además de las incursiones de elementos armados de sus propias Fuerzas Armadas y otros grupos militares y paramilitares.

12 La República Democrática del Congo y Colombia han sufrido — y siguen sufriendo — graves abusos de derechos humanos y crímenes internacionales perpetrados después de las fechas de ratificación a la Corte Penal Internacional, producidas respectivamente el 11 de abril de 2002 y el 5 de agosto de 2002.

13 Miembros de la Oficina de la Fiscalía de la Corte Penal Internacional (CPI) y de otros órganos de la Corte han estado presentes en diversas ocasiones y maneras a lo largo de las conversaciones de paz de La Habana; además, se tiene en cuenta que la situación de Colombia era objeto de investigaciones preliminares desde el año 2004 por parte de esa Oficina. Corte Penal Internacional, Oficina de la Fiscalía, "Informe sobre las actividades de examen preliminar de 2014 (situaciones en Honduras y Colombia)", https://www.icc-cpi. int/iccdocs/otp/OTP-Hon-Col-2014.PDF (acceso mayo 23, 2017). Como culminación de dicho seguimiento a las conversaciones de paz, la fiscal jefe de la CPI ha puesto de manifiesto que seguirá de cerca la implementación de las cuestiones de justicia sobre el acuerdo de paz, calificado como acuerdo histórico: "El anuncio del 24 de agosto de 2016 sobre la conclusión de las negociaciones de paz entre el Gobierno de Colombia y las Fuerzas Armadas Revolucionarias de Colombia-Ejército del Pueblo ('FARC-EP') es sin lugar a dudas un logro histórico para Colombia y para el pueblo colombiano, cuyas vidas se han visto profundamente afectadas por el conflicto armado de 52 años. Saludo el anuncio del acuerdo final de paz como un paso crucial hacia el fin del prolongado conflicto durante el cual numerosas atrocidades fueron presuntamente cometidas por todas las partes. Esta oportunidad única para la paz marca el comienzo de un proceso a largo plazo que requerirá un esfuerzo decidido en el curso de su implementación. Comparto la esperanza de que este acuerdo de paz será la base para la construcción de una paz duradera en Colombia. El pueblo de Colombia no merece nada menos". Corte Penal Internacional, "Declaración de la fiscal de la CPI, Fatou Bensouda, sobre la conclusión de las negociaciones de paz entre el Gobierno de Colombia y las Fuerzas Armadas Revolucionarias de Colombia-Ejército del Pueblo", https://www.icc-cpi.int/Pages/item. aspx?name=160901-otp-stat-colombia\&ln=Spanish (acceso mayo 23, 2017). 
La información oficial de la CPI sostiene que Colombia está entre los catorce casos del mundo que son objeto de exámenes preliminares por parte de la Fiscalía de esa Corte. ${ }^{14}$ La posible intervención de la CPI ha condicionado la gestión del conflicto violento a partir de 2002 y quizás condicionará también la gestión del posconflicto. ${ }^{15}$

Independientemente del gran impacto del conflicto sobre la población, desde mediados del siglo pasado, a partir de 2002 existen numerosos hechos que pueden ser investigados por la CPI — dados los tres grandes crímenes que le competen: genocidio, crímenes contra la humanidad y crímenes de guerra-, como asesinatos, secuestros y otras formas graves de privación de libertad, desapariciones forzadas, reclutamiento forzado de menores, traslado forzoso de personas, torturas y violaciones sistemáticas, por parte de guerrillas y paramilitares y asesinatos conocidos como "falsos positivos" (asesinato de civiles que hacen pasar por guerrilleros muertos en combate), desapariciones forzadas y torturas, por parte del Ejército de Colombia y otras fuerzas públicas colombianas o grupos bajo el manto de la autoría mediata.

Esta realidad parcial de la confrontación es compleja, si se tiene en cuenta el aspecto sensible de las amnistías, ya destacado. En el caso colombiano ha resultado especialmente delicado el contenido de las conversaciones de paz en La Habana y los posibles acuerdos en materia de amnistía ${ }^{16}$ en relación con hechos que pudieran ser calificados como crímenes internacionales de guerra o contra la humanidad, cometidos desde 2002 hasta el presente.

14 La Fiscalía de la CPI hace exámenes preliminares en relación con los siguientes países: Afganistán, Burundi, Colombia, Gabón, Guinea, Iraq/Reino Unido, Nigeria, Palestina, República Centroafricana y Ucrania, así como la Unión de las Comoras, Camboya y Ucrania. Corte Penal Internacional, "Preliminary Examinations", https://www.icc-cpi.int/pages/preliminary-examinations.aspx (acceso mayo 23, 2017).

15 El Acuerdo final del 24 de noviembre de 2016 hace expresa referencia a la Corte Penal Internacional y sus Estatutos, de los que Colombia es Estado parte: "Teniendo presente que el nuevo Acuerdo Final recoge todos y cada uno de los acuerdos alcanzados en desarrollo de la agenda del Acuerdo General suscrita en La Habana en agosto de 2012; y que para lograrlo, las partes, siempre y en cada momento, se han ceñido al espíritu y alcances de las normas de la Constitución Nacional, de los principios del Derecho Internacional, del Derecho Internacional de los Derechos Humanos, del Derecho Internacional Humanitario (Convenios y Protocolos), de lo mandado por el Estatuto de Roma (Derecho Internacional Penal), de los fallos proferidos por la Corte Interamericana de Derechos Humanos relativos a los conflictos y su terminación, y demás sentencias de competencias reconocidas universalmente y pronunciamientos de autoridad relativos a los temas suscritos [...]". Gobierno Nacional y Fuerzas Armadas Revolucionarias de Colombia-Ejército del Pueblo, "Acuerdo final para la terminación del conflicto y la construcción de una paz estable y duradera", 2.

16 Para ver el alcance de la influencia de los Estatutos de la Corte Penal Internacional en el Acuerdo final, en particular a amnistía e investigación de hechos criminales, Gobierno Nacional y Fuerzas Armadas Revolucionarias de Colombia-Ejército del Pueblo, "Acuerdo final para la terminación del conflicto y la construcción de una paz estable y duradera", 148, 151, 169, 295, 298, 304, 306, 308 y concordantes. 


\section{Acuerdo final para la terminación del conflicto y la construcción de una paz estable y duradera}

Después de más de cuatro años de diálogos, encuentros, conversaciones, negociaciones y acuerdos parciales, el 24 de agosto de 2016 se hizo público un acuerdo global alcanzado sobre todos los puntos de la agenda establecida por los representantes del Gobierno de Colombia y de las Fuerzas Armadas Revolucionarias de Colombia (FARC). Un mes después, el 26 de septiembre de 2016, dicho Acuerdo se firmó solemnemente en Cartagena de Indias ante 250 víctimas procedentes de diversas localidades colombianas y 2.500 invitados nacionales e internacionales, entre ellos, presidentes de diversos países y el secretario general de la Organización de las Naciones Unidas. ${ }^{17}$

Puesto que con las conversaciones de paz se quería acabar con más de cinco décadas de conflicto armado, sin tener necesidad legal, el presidente de Colombia convocó a los colombianos residentes en el país y exiliados a un plebiscito, en busca de la legitimación popular del pacto. El acto contó con una baja participación de la ciudadanía colombiana y se obtuvo un resultado negativo por un escaso margen de votos, ${ }^{18}$ aun cuando los votantes de los territorios más victimizados y más afectados por la violencia sistemática $-\mathrm{y}$, por tanto, más preocupados porque no hubiera impunidad — votaron mayoritariamente a favor.

La negativa plebiscitaria tuvo como consecuencia la integración de mesas negociadoras con algunos representantes políticos y cívicos que habían rechazado el Acuerdo de paz (por determinadas condiciones de amnistía ${ }^{19}$ o exclusiones de responsabilidad

17 La firma solemne del Acuerdo de paz tuvo una gran cobertura global de medios: el presidente de Colombia y el representante de las FARC firmaron con un "balígrafo" (bala convertida en bolígrafo), se estrecharon las manos y pidieron disculpas a las víctimas. "What we sign today is a declaration from the Colombian people before the world that we are tired or war [...] that we don't accept violence as the means of defending ideas [...]. Let no one doubt that we will now pursue politics without weapons". Nicholas Cassey, "Colombia Signs Peace Agreement with FARC after 5 Decades of War", New York Times, 26 de septiembre de 2016, http://www.nytimes.com/2016/09/27/world/americas/colombia-farc-peace-agreement.html?_r=0 (acceso mayo 23, 2017).

18 Sibylla Brodzinsky, "Colombia Referendum: Voters Reject Peace Deal with FARC Guerrillas", The Guardian, 2 de octubre de 2016, https://www.theguardian.com/world/2016/oct/02/colombia-referendum-rejects-peace-deal-with-farc (acceso octubre 3, 2016). Un somero análisis del resultado del referendo puso de manifiesto que un $62 \%$ de los votantes colombianos se había abstenido de votar, lo que posibilita diversas interpretaciones del mismo y rechaza el desinterés de los colombianos como causa de esta mayoritaria abstención. Jordi Palou-Loverdos, "Colòmbia: elogi del diàleg", ara.cat, 3 de octubre de 2016, http://www. ara.cat/opinio/Colombia-elogi-del-dialeg_0_1662433754.html (acceso mayo 23, 2017).

19 Conviene recordar las numerosas resoluciones de la Corte Interamericana de Derechos Humanos que fijan límites a la impunidad y a las leyes de amnistía que tuvieron predicación por varios países de América Latina: 
penal por los crímenes y la participación política de los excombatientes, entre otros), con el fin de incorporar propuestas y mejorar algunos puntos controversiales del extenso texto.

Tras varias semanas de negociación y revisión de aspectos relevantes de 54 de los 57 ejes temáticos del pacto, el 24 de noviembre de 2016 se firmó en Bogotá ante legisladores y embajadores el "Acuerdo final para la terminación del conflicto y la construcción de una paz estable y duradera". ${ }^{20}$

Los firmantes y los ciudadanos colombianos saben que el reto verdadero es la implementación de lo acordado en todo el territorio nacional, que se inicia a partir de ahora, así como culminar procesos exploratorios conducentes a la paz con otros grupos armados como el Ejército de Liberación Nacional (ELN), a sabiendas de que lo firmado no constituye la paz, sino las vías trazadas para acabar con el conflicto armado y generar nuevas condiciones de convivencia y paz estable.

\section{Esclarecimiento de la verdad, políticas e iniciativas de memoria del Acuerdo de paz}

El conflicto armado de Colombia enfrenta notables retos en los campos de verdad, justicia, reparación y garantías de no repetición. No se puede analizar aquí un Acuerdo definitivo de paz de 310 páginas que crea un sistema complejo de mecanismos jurisdiccionales y no jurisdiccionales de justicia transicional. Se revisan someramente algunos de los mecanismos que hacen explícita referencia a

"Esta Corte considera que son inadmisibles las disposiciones de amnistía, las disposiciones de prescripción y el establecimiento de excluyentes de responsabilidad que pretendan impedir la investigación y sanción de los responsables de las violaciones graves de los derechos humanos tales como la tortura, las ejecuciones sumarias, extralegales o arbitrarias y las desapariciones forzadas, todas ellas prohibidas por contravenir derechos inderogables reconocidos por el Derecho Internacional de los Derechos Humanos [...]; —Declarar que las leyes de amnistía No 26479 y No 26492 son incompatibles con la Convención Americana sobre Derechos Humanos y, en consecuencia, carecen de efectos jurídicos. —Declarar que el Estado del Perú debe investigar los hechos para determinar las personas responsables de las violaciones de los derechos humanos a los que se ha hecho referencia en esta Sentencia, así como divulgar públicamente los resultados de dicha investigación y sancionar a los responsables [...]". Corte Interamericana de Derechos Humanos, Caso Barrios altos vs. Perú. Sentencia de 7 de septiembre de 2012.

20 Gobierno Nacional y Fuerzas Armadas Revolucionarias de Colombia-Ejército del Pueblo, "Acuerdo final para la terminación del conflicto y la construcción de una paz estable y duradera", nota al pie No. 1. Ver al respecto la noticia de la aprobación y ratificación política de los acuerdos por parte del Congreso colombiano en "El Congreso de Colombia aprueba el acuerdo de paz firmado con las FARC", eldiario. es, 1 de diciembre de 2016, http://www.eldiario.es/internacional/Congreso-Colombia-acuerdo-firmadoFARC_0_586191546.html (acceso mayo 23, 2017). 
la denominada "memoria histórica", en relación con las víctimas y con el conflicto en su conjunto.

Ya hemos señalado el importante coraje político que ha supuesto llevar a cabo iniciativas de memoria en medio de la confrontación, tanto desde la perspectiva de las víctimas y comunidades afectadas como las iniciativas públicas nacionales, regionales y locales.

La memoria histórica se conceptúa en el Acuerdo como parte integrante de un sistema particular para la situación de Colombia, no como algo aislado ni estandarizado. Así, la memoria histórica está integrada en el Sistema integral de verdad, justicia, reparación y no repetición establecida en el texto. ${ }^{21}$

Uno de los aspectos destacados del Acuerdo final recoge la creación de la Comisión para el esclarecimiento de la verdad, la convivencia y la no repetición.

El fin del conflicto constituye una oportunidad única para satisfacer uno de los mayores deseos de la sociedad colombiana y de las víctimas en particular: que se esclarezca y conozca la verdad sobre lo ocurrido en el conflicto. Colombia necesita saber qué pasó y qué no debe volver a suceder nunca más, para forjar un futuro de dignificación y de bienestar general y así contribuir a romper definitivamente los ciclos de violencia que han caracterizado la historia de Colombia. En este nuevo escenario será posible aportar a la construcción y preservación de la memoria histórica y lograr un entendimiento amplio de las

21 Hasta tal punto ha tomado relevancia este enfoque holístico y de visión de complementariedad, que el Consejo de Derechos Humanos de Naciones Unidas acordó crear una relatoría especial con mandato específico sobre los ejes de "verdad, justicia, reparación y garantías de no repetición". El Consejo encomienda al relator especial del mismo nombre un enfoque global de esos cuatro pilares con el fin de "garantizar la rendición de cuentas, hacer justicia, brindar vías de recurso a las víctimas, fomentar la recuperación de la normalidad y la reconciliación, establecer entidades independientes que supervisen los sistemas de seguridad, restablecer la confianza en las instituciones del Estado y promover el Estado de derecho de conformidad con las normas internacionales de derechos humanos". Gobierno Nacional y Fuerzas Armadas Revolucionarias de Colombia-Ejército del Pueblo, "Acuerdo final para la terminación del conflicto y la construcción de una paz estable y duradera", punto 5.1. Este mismo enfoque ha sido asumido, razonado y argumentado por el primer relator nombrado, el colombiano Pablo de Greiff. En su primer informe, del 9 de agosto de 2012, pone especial énfasis en el enfoque global y la necesaria interrelación de los cuatro elementos que son objeto de mandato y correlaciona además de dos objetivos mediatos -el reconocimiento a las víctimas y las medidas de confianza- y dos objetivos finales — contribuir a la reconciliación y consolidar el Estado de derecho-; explica en forma detallada que cada uno de los cuatro elementos debe ser considerado para la consecución de todos ellos. Comité de Derechos Humanos, Report of the Special Rapporteur on the Promotion of Truth, Justice, Reparation and Guarantees of Non-Recurrence, Pablo de Greiff, http://www.ohchr.org/ Documents/HRBodies/HRCouncil/RegularSession/Session21/A-HRC-21-46_en.pdf (acceso mayo 23, 2017). 
múltiples dimensiones de la verdad del conflicto, incluyendo la dimensión histórica, de tal forma que no sólo se satisfaga el derecho a la verdad sino que también se contribuya a sentar las bases de la convivencia, la reconciliación, y la no repetición. ${ }^{22}$

Se trata de un mecanismo independiente y de carácter extrajudicial que forma parte del Sistema integral de verdad, justicia, reparación y no repetición antes referido, "acordado para satisfacer los derechos de las víctimas, terminar el conflicto y alcanzar la paz". ${ }^{23}$

El convenio establece que dicha comisión debe contribuir al esclarecimiento y a la comprensión compartida del conflicto y, en particular, de sus aspectos más desconocidos y ocultos, incluido su impacto sobre los niños, las niñas, los jóvenes y la violencia de género. Asimismo, se pretende que sea una plataforma adecuada para el reconocimiento institucional a las víctimas del conflicto, sin distinción, con el fin de facilitar el rechazo a las diversas dinámicas violentas producidas durante el conflicto para que no se repitan.

No se trata de un mero ejercicio descriptivo de hechos — violaciones masivas de derechos humanos o de derecho internacional humanitario- o la simple construcción de un nuevo relato compartido, ${ }^{24}$ sino una aproximación a la memoria histórica que debe orientarse hacia la convivencia en las diferencias — conocidas y reconocidasa la resolución pacífica de conflictos y a la reconciliación. ${ }^{25}$

En relación con el eje "Reparación" del Sistema integral, el pacto prevé que los planes de reparación colectiva con enfoque territorial recojan y trabajen de forma específica "la memoria", entre sus medidas materiales y simbólicas para atender el

22 Comite de Derechos Humanos, Report of the Special Rapporteur on the Promotion of Truth, Justice, Reparation and Guarantees of Non-Recurrence.

23 Comité de Derechos Humanos, Report of the Special Rapporteur on the Promotion of Truth, Justice, Reparation and Guarantees of Non-Recurrence.

24 El propio Acuerdo final prevé que las conclusiones adoptadas por la Comisión independiente para el esclarecimiento de la verdad, la convivencia y la no repetición sean tenidas en cuenta por la institución pública Centro Nacional de Memoria. Gobierno Nacional y Fuerzas Armadas Revolucionarias de Colombia-Ejército del Pueblo, "Acuerdo final para la terminación del conflicto y la construcción de una paz estable y duradera", 136.

25 En el punto relativo a las medidas de restitución de tierras se hace explícita referencia a la construcción de procesos de memoria histórica orientados a la reconciliación. Gobierno Nacional y Fuerzas Armadas Revolucionarias de Colombia-Ejército del Pueblo, "Acuerdo final para la terminación del conflicto y la construcción de una paz estable y duradera”, punto 5.1.3.6. 
daño. A tal efecto deben preverse "acciones de dignificación, de memoria, homenajes y conmemoraciones, obras de infraestructura y arquitectura conmemorativa". ${ }^{26}$

En el Acuerdo final se hallan claros compromisos de políticas de memoria a implementar por el Gobierno colombiano. Así, por ejemplo, el Gobierno se obliga a elaborar un mapa de victimización individual y colectivo como instrumento de reconocimiento y memoria, ${ }^{27}$ en sinergia con los mecanismos jurisdiccionales y no jurisdiccionales creados por él. Ello tiene especial relevancia para el conocimiento y reconocimiento de las personas desaparecidas en el marco del conflicto y para dimensionar la intensidad de los ataques a los derechos humanos, con el propósito de que el pueblo colombiano conozca el verdadero alcance de más de cinco décadas de violencia y pueda dignificar a las víctimas preservando su memoria desde las instituciones públicas y desde la sociedad civil.

\section{Reflexiones finales}

En cumplimiento de sus respectivas misiones institucionales y cívicas, las entidades nacionales, regionales y locales colombianas tienen el reto de aportar sus conocimientos y experiencias para la implementación de los acuerdos de paz en los territorios. Para las personas, los colectivos, las organizaciones, los Gobiernos, las estructuras de poder y los pueblos, es un desafío compartido desplegar el abanico de mecanismos transicionales adecuados a una situación concreta de conflicto armado, violencia o de abusos de derechos humanos. Se trata de dar pasos hacia una cultura de la paz que permita canalizar los conflictos emergentes o latentes de forma no violenta y generar condiciones de armonía catalizadora de transformaciones profundas de sistemas injustos, desiguales o violentos.

La memoria constituye uno de los pilares de la conciencia individual y colectiva y de la convivencia en las diferencias, para prevenir repeticiones lesivas y violentas. La aproximación a Colombia nos permite observar dinámicas y estrategias diversas y nos lleva a concluir, una vez más, que no existe un modelo universal de gestión de situaciones posconflicto bélico o posdictadura. Cada situación, cada país y cada pueblo deben singularizar los canales y mecanismos más adecuados que, desde perspectivas combinadas jurisdiccionales y no jurisdiccionales, faciliten enfrentar

\footnotetext{
Gobierno Nacional y Fuerzas Armadas Revolucionarias de Colombia-Ejército del Pueblo, "Acuerdo final para la terminación del conflicto y la construcción de una paz estable y duradera", punto 5.1.3.3.2.

27 Gobierno Nacional y Fuerzas Armadas Revolucionarias de Colombia-Ejército del Pueblo, "Acuerdo final para la terminación del conflicto y la construcción de una paz estable y duradera", punto 5.1.3.7.
} 
los abusos del pasado para transformar la situación, sin olvidos ni resentimientos, pero con esclarecimiento, honestidad, justicia, memoria y reparación. Son nuevos horizontes equitativos, democráticos y preservadores de derechos de forma sostenida; horizontes deseados por las personas, las instituciones y los pueblos afectados, por el bien de las generaciones presentes y futuras. Esperamos que así sea para Colombia.

\section{Referencias}

"El Congreso de Colombia aprueba el acuerdo de paz firmado con las FARC". eldiario. es, 1 de diciembre de 2016. http://www.eldiario.es/internacional/Congreso-Colombiaacuerdo-firmado-FARC_0_586191546.html (acceso mayo 23, 2017).

Cassey, Nicholas. "Colombia Signs Peace Agreement with FARC after 5 Decades of War". New York Times, 26 de septiembre de 2016. http://www.nytimes.com/2016/09/27/ world/americas/colombia-farc-peace-agreement.html?_r=0 (acceso mayo 23, 2017). Comité de Derechos Humanos, Report of the Special Rapporteur on the Promotion of Truth, Justice, Reparation and Guarantees of Non-Recurrence, Pablo de Greiff, http://www.ohchr. org/Documents/HRBodies/HRCouncil/RegularSession/Session21/A-HRC-21-46_en.pdf (acceso mayo 23, 2017).

Congreso de la República de Colombia. Ley 975 de 2005, "Por la cual se dictan disposiciones para la reincorporación de miembros de grupos armados organizados al margen de la ley, que contribuyan de manera efectiva a la consecución de la paz nacional y se dictan otras disposiciones para acuerdos humanitarios". Bogotá: Diario Oficial No. 45.980, 25 de julio de 2005.

Corte Interamericana de Derechos Humanos. Caso Barrios altos vs. Perú. Sentencia de 7 de septiembre de 2012.

Corte Penal Internacional, Oficina de la Fiscalía. "Informe sobre las actividades de examen preliminar de 2014 (situaciones en Honduras y Colombia)". https://www.icc-cpi.int/ iccdocs/otp/OTP-Hon-Col-2014.PDF (acceso mayo 23, 2017).

Corte Penal Internacional. "Declaración de la fiscal de la CPI, Fatou Bensouda, sobre la conclusión de las negociaciones de paz entre el Gobierno de Colombia y las Fuerzas Armadas Revolucionarias de Colombia-Ejército del Pueblo". https://www.icc-cpi.int// Pages/item. aspx?name=160901-otp-stat-colombia\&ln=Spanish (acceso mayo 23, 2017).

Corte Penal Internacional. "Preliminary Examinations". https://www.icc-cpi.int/pages/ preliminary-examinations.aspx (acceso mayo 23, 2017).

Gobierno Nacional y Fuerzas Armadas Revolucionarias de Colombia-Ejército del Pueblo. "Acuerdo final para la terminación del conflicto y la construcción de una paz estable y duradera". http://www.altocomisionadoparalapaz.gov.co/procesos-y-conversaciones/ 
Documentos\%20compartidos/24-11-2016NuevoAcuerdoFinal.pdf (acceso mayo 23, 2017).

Gobierno Nacional y Fuerzas Armadas Revolucionarias de Colombia-Ejército del Pueblo. "Acuerdo general para la terminación del conflicto y la construcción de una paz estable y duradera". http://www.altocomisionadoparalapaz.gov.co/procesos-y-conversaciones/ acuerdo-general/Documentos\%20compartidos/Acuerdo_General_para_la_terminacion_del_conflicto.pdf (acceso mayo 23, 2017).

Gómez Isa, Felipe. Paramilitary Demobilization in Colombia: Between Peace and Justice, documento de trabajo núm. 57, editado por Fride. http://www.fride.org/download/ WP57_Colombia_Desmili_ENG_abr08.pdf (acceso mayo 23, 2017).

Grupo de Memoria Histórica. ¡Basta ya! Colombia: memorias de guerra y dignidad. Bogotá: Centro Nacional de Memoria Histórica y Departamento para la prosperidad social, 2016. Moreno, Carolina. "Denuncian asesinato de 94 líderes sociales en 2016". http://www. centrodememoriahistorica.gov.co/noticias/noticias-cmh/van-94-los-lideres-socialesasesinados-en-el-2016 (acceso mayo 23, 2017).

Palou-Loverdos, Jordi. "Colòmbia: elogi del diàleg". ara.cat, 3 de octubre de 2016. http:// www.ara.cat/opinio/Colombia-elogi-del-dialeg_0_1662433754.html (acceso mayo 23, 2017).

Sibylla Brodzinsky, "Colombia Referendum: Voters Reject Peace Deal with FARC Guerrillas", The Guardian, 2 de octubre de 2016, https:/www.theguardian.com/world/2016/ oct/02/colombia-referendum-rejects-peace-deal-with-farc (acceso octubre 3, 2016). 